\title{
Gender (In)Consistent Communication via Social Media and Hireability: An Exploratory Study
}

\author{
Robyn L. Brouer \\ Canisius College \\ robyn.brouer@canisius.edu
}

\author{
Michael A. Stefanone \\ University at Buffalo \\ ms297@buffalo.edu
}

\author{
Rebecca L. Badawy \\ Youngstown State Univ. \\ rbadawy@ysu.edu
}

\author{
Michael J. Egnoto \\ University of Maryland \\ megnoto@umd.edu
}

\begin{abstract}
Using social media in employee selection processes is relatively new behavior that raises many important questions. Although managers report using sites like Facebook to review applicants, little is known about how these sites influence assessments of those candidates. This exploratory study reports on an experiment designed to evaluate competing hypotheses regarding (in)consistent gender normbased communication on Facebook and subsequent attraction and hiring decisions. All participants were required to have been responsible for actual hiring decisions during their careers. Surprisingly, results are in contrast to research on the selection process and show that feminine-style communication on Facebook is perceived as most attractive and hirable. However, masculine communication is perceived as least attractive and hirable. This effect was consistent regardless of applicant gender. Practical implications, strengths, limitations, and directions for future research are discussed.
\end{abstract}

\section{Introduction}

Humans are generally skilled and strategic about how they present themselves to specific audiences. We actively work to manage the impressions we make on others [37], and social media provide novel venues for self-disclosure, self-presentation, and impression management. The processes of selfpresentation - the information we share about ourselves, and how we react to others' disclosureshave consequences for our friendship and professional networks.

Social network sites (SNS) are becoming the standard for sharing information and maintaining relationships of all kinds. Among popular SNS, Facebook remains the dominant form of communication. With over 1.5 billion active accounts, Facebook is 15 times larger than LinkedIn, and has more active users than any other social media platform [55]. From the communication sender perspective, research has evaluated a range of presentation-related behavior including specific strategies for presentation of self and the management of other-generated information [17]. Research also focuses on receivers. For example, Vitak [19] discussed how individuals manage the scope of their networks in an effort to minimize fallout related to having multiple audiences [14], which highlights the difficulty communicating simultaneously with diverse audiences that may have differing expectations for how those individuals communicate.

Younger adults are generally the most invested in social media [16] and are most likely seeking professional employment for the first time. As a consequence of these two conditions, individual user profiles accessible via SNS are becoming increasingly rich and tempting information sources for human resources (HR) managers faced with making hiring decisions [41]. Our social media footprints may offer valuable information beyond our carefully constructed resumes that can help employers more efficiently and effectively screen applicants. Not surprisingly, precisely this kind of social media-focused screening is becoming common practice among HR managers, regardless of the legal and ethical implications. For example, $22 \%$ of HR managers reported using Facebook as a screening tool in 2008 , compared to $70 \%$ of managers who indicated they had actually rejected job applicants on the basis of information available about those applicants via social media in 2012 [44]. This represents a striking increase in the use of social media for applicant screening.

The use of sites like Facebook by employers making hiring decisions is becoming increasingly important because young individuals are the most likely to identify with a culture of celebrity, which translates into generally uninhibited self-disclosure of personal information online [29]. These profiles afford a clear window employers can leverage to observe job applicants 'in the wild.' However, research into understanding how specific elements of user profiles influence employment decisions has been lacking, focusing instead on personality [44].

Previous research shows systematic differences in online self-presentation based on gender norms 
persist online. Specifically, women tend to present themselves via social media as nurturing and familial, while men more frequently engage in self-promotion, accentuating their status and accomplishments [48]. Therefore, the characteristics of nurturing and selfpromoting, when applied to Facebook pages, can be categorized as either feminine or masculine, respectively. Although we acknowledge recent work has moved beyond a gender binary, due to the exploratory nature of this study, we explore feminine versus masculine and use the terms male/man and female/woman interchangeably.

According to Social Role Theory [2], adherence to gender norms is (often subconsciously) expected. Outside the realm of SNS, studies show that violations of gender norms during the hiring process (e.g., a woman using self-promotion) result in less favorable impressions and hiring decisions [23]. However, because SNS offer individuals the ability to be increasingly uninhibited, they may feel more comfortable violating common gender norms, creating more accurate presentations of themselves [12], especially because many of these sites are not geared toward employment per se (the exception, LinkedIn). The question then becomes, will violations of gender norms found on SNS result in the same negative consequences as we see in other facets of the hiring process (e.g., resumes, interviews), or will these violations be perceived as authentic (a person being true to themselves) and thus demonstrate positive consequences? Our goal with this exploratory study is to investigate the effects of gender (in)consistent presentation of self via social media on perceived job applicant attractiveness.

Below, we review literature on self-presentation, social norms, and self-presentation. Competing hypotheses are developed to test these questions. We report the results of an experiment followed by a general discussion.

\section{Self-presentation and social norms}

Self-presentation is the process individuals use to control others' perceptions of them [37]. Everyone is motivated to present themselves in ways that verify their self-concept [49], but also are agreeable to their audience so that they create and maintain positive images of themselves [11].

These self-presentations are often consciously and subconsciously managed to be consistent with stereotypical social norms. For instance, Eagly's [2] social role theory is useful for understanding the behaviors that are expected and prescribed to different genders. These gender roles are socially constructed and provide different genders the expectations that others have of them, as well as beliefs about how they should behave. Gender norms are so pervasive that even when individuals do not personally ascribe to them, they may feel forced to display normative gender behaviors [8].

Therefore, men and women are expected to behave differently; this leads to differences in actual behavior and reactions to those behaviors. Women are expected to be communal, caring, dependent, and empathetic, whereas men are expected to be agentic, assertive, controlling, and unemotional. Further, in work settings, men are expected to be competent, and women are expected to be warm [51, 47]. The stereotype-content model [47] explains that individuals who engage in assertive, independent behaviors are perceived as more competent. Individuals engaging in accommodating behaviors are seen as warm [8]. Based on gender norms, men are seen as more competent because they tend to use assertive behaviors. Women are seen as warm because they tend to behave communally.

When either gender displays behaviors counter to these stereotypes (e.g., women behaving assertively; men behaving empathetically), backlash occurs, and backlash stemming from counternormative behavior tends to be stronger for women [8]. This backlash can occur when women use behaviors such as selfpromotion or intimidation [31, 21]. A woman who displays competence tends to be unliked and seen as having lower social skill, and ultimately less attractive to employers [21, 23].

Expectancy violation theory [15] explains why women experience stronger and more frequent backlash $[8,34,22]$ by describing two types of violations that occur from gender counter-normative behavior: positive and negative. Positive violations are often experienced by men and happen when someone who is supposed to behave agentically, instead behaves cooperatively [13]. Because positive violations involve someone acting in a more accommodating manner than expected, they can elicit positive reactions from others or, at the least, less severe negative reactions. Women, more typically, experience negative violations, which occur when someone who is supposed to behave in a communal fashion, instead engages in competitive, competent, agentic behavior. Negative violations, which involve someone acting more competitively than expected, create negative emotions in the other party $[47,8]$.

This produces an interesting conundrum for women during the hiring process. The influence 
tactic of self-promotion, which involves creating an image of competence, is generally necessary during job interviews. However, as mentioned previously, women who display competence during job interviews are less liked and seen as less socially skilled and hirable [21, 23]. For instance, competent communication styles used by female job applicants were seen as less persuasive and less hirable to hiring executives than women using less competent communication [10]. This same study found that men who used a competent communication style were seen as the most persuasive and hirable because engaging in behaviors that signal competence (e.g., self-promotion) is normative for men.

Additionally, women using less competent styles of communication were more able to influence both their female and male peers, and men who spoke competently were more influential than those that spoke indirectly [25]. Together, these studies suggest that "when women exhibit the exact same competent behavior as men do, even though that behavior is, in fact, perceived to convey competence in women as well as men, women still remain at a disadvantage" [26, p. 731]. In negotiation or interview situations, when women communicate a desire for personal gain (getting a better salary or a job offer), they are likely to be ineffective $[35,4]$.

Further, although dominant, threatening behaviors are not seen as particularly influential for either men or women, because those behaviors are more expected of men, women will be more disliked and lacking influence when using these behaviors [26], experiencing a negative violation. Men behaving this way are not behaving counter-normatively, and thus are less likely to experience backlash and negative consequences.

\subsection{Self-presentation on social media}

Social media use enables new sets of selfpresentation behaviors because of the affordances that differentiate these media from traditional offline communication. Born out of perceived anonymity and developing into a rich and asynchronous selfpresentation tool, it can be argued that SNS are less constrained environments (and thus have reduced gender-normative pressures) than traditional offline contexts.

Early computer-mediated communication (CMC) was characteristically more anonymous, which facilitated play and identity exploration. Because socially normative influence is lower when individuals are not identifiable [33], early CMC users were not constrained to traditional gender norms and were free to experiment with their identity online.

Today's internet-based communication tools are much richer in comparison, reducing or even eliminating anonymity. It is standard practice to include accurate, recent images of one's self on profile pages, and SNS typically enable users to disclose their hometown, relationship status, and a range of entertainment preferences. Despite this, there is evidence that the Internet (i.e., SNS) remains an exploration ground, where users feel less constrained and therefore can use it to discover and negotiate their true identity [24].

Even more importantly, SNS allow users to present themselves asynchronously. According to social impact theory [5], these factors likely reduce gender normative influence because the "immediacy" (proximity of space and time) of members is reduced as compared to face-to-face (FTF) interactions.

These asynchronous communication tools include profiles with multiple modes of communication such as text, images, and videos, affording users relatively new opportunities to present themselves through a range of communication modes. Users frequently update their status and even 'check in' to physical locations around the world, notifying their networks about where they are, what they are doing, and how they feel. It follows then that SNS allow for more detailed self-descriptions than one would be able to communicate in a casual offline interaction at any one point [39].

Taken together, uninhibited self-disclosure and rich multimodal tools for self-presentation may combine to facilitate increasingly unconstrained communication, reducing gender normative pressure for SNS users. Providing preliminary support, research shows that SNS users present themselves in a more accurate and authentic manner through social media as compared to offline settings, relying less on socially prescribed roles [24]. In today's culture of celebrity [29], individual's online personas are tightly and intimately tied to their offline selves, and our online performances are most often accurate, if idealized, presentations of ourselves [12].

Consequently, SNS users rely less on socially prescribed norms and more on the self to guide behavior. This holds true for gender norms. Recent research suggests that individuals do not always present themselves in gender stereotypical ways on SNS. Oberst and colleagues [52] surveyed nearly 800 adolescent Facebook users and found that users were 
less likely to follow gender-based norms when engaging in self-presentation online. Consistent with Shapiro and Margolin [24], the authors argued that SNS platforms enable users to explore and shape their identity devoid of constraints set by pervasive social norms. Such exploring behavior is linked to the creation of an ideal self, or an online representation of who these users want to be [50].

This evidence raises questions about how different kinds of self-presentation behavior is interpreted by potential employers in job-seeking scenarios. Recall that in offline settings, there are negative consequences for individuals who behave counter to their normative behaviors (i.e., backlash effect), making offline contexts constrained. However, as discussed above, SNS are unconstrained, in which "many behaviors are considered appropriate, and little negative feedback is received if a norm is violated" [43, p. 491]. Thus, the backlash effect is less pronounced on SNS, affording woman, and men opportunities to self-present in ways both consistent and inconsistent with gender norms. The question remains: do hiring managers perceive inconsistent gender posts on SNS as negative, leading to lower attraction? Or, do hiring managers perceive these inconsistencies as authentic and thus have increased attraction to the job candidate.

\section{Hypothesis development}

Walster et al. [54] defined interpersonal attraction as "an individual's tendency or predisposition to evaluate another person or the symbol of the person in a positive (or negative) way" (p.3), consisting of social (I want to be friends with this person) and task (this person is competent) attraction. The central notion is that when person $\mathrm{A}$ is attracted to person $\mathrm{B}$, person A will seek opportunities to interact with person $\mathrm{B}$, and person $\mathrm{B}$ will have interpersonal power (or influence) over person A [53].

In FTF communication and in much of the research on selection, gender consistent communication is seen as more attractive [e.g., 21, 23]. Based on social role theory, communication on Facebook that is consistent with gender roles should result in higher social attraction. Thus, males selfpromoting and intimidating on SNS should be viewed as normative and attractive. Women using accommodating and communal language will be seen as normative and attractive. Of these inconsistent categories, we would expect women behaving in an agentic, self-promotional way to be seen as the least attractive because this is a negative violation $[47,8]$. Thus,

H1: Gender role consistent self-presentation on SNSs has a positive relationship with perceived social and task attraction.

However, as argued above, SNS are essentially unfiltered windows into the true selves of job applicants. It may be the case that hiring managers recognize the authenticity of this information (opposed to exaggerations commonly found on resumes), which may lead to positive feelings about job applicants. For example, there is an established link between honest self-presentation and positive outcomes in the workplace [6], and researchers have found that personality can be accurately predicted using Facebook [32]. Because hiring managers view information available via social media as honest and unconstrained, where individuals present their actual selves, whether or not self-presentation is consistent with gender norms should matter less. Access to authentic information about applicants should be perceived as trustworthy, which should lead to increased attractiveness as reactions will be based on perceptions of the individual's actual personality, behaviors, and attitudes especially when that information is inconsistent with gender norms. Indeed, sincere, honest, and trustworthy individuals are considered more attractive [e.g., 38, 6]. Thus,

H2: Gender role inconsistent self-presentation on SNS has a positive relationship with perceived social and task attraction.

Attraction is one of the strongest and most pervasive influence tactics [42]. When you find someone attractive, you are more likely to do what he or she wants [42]. Hence, managers will be more likely to hire job applicants that are considered socially and task attractive. Indeed, numerous studies have found a link between applicant attraction and hiring decisions $[36,7,3,9]$. Thus,

H3: Evaluations of a] social and b] task attraction have positive relationships with hiring ratings.

\section{Methods}

Participants were recruited from the online survey panel, Amazon's Mechanical Turk (MTurk). MTurk employs over 500,000 "workers" (i.e., survey takers), providing a large participant pool that is generally more diverse than college or other Internet samples, 
with workers coming from a variety of places, and representing more ethnic backgrounds than most college samples can produce [30]. Because of this, MTurk has been considered an ideal sample source for experimental and social scientific work [30]. MTurk tracks workers' performance and provides scores based on this performance. Researchers are able to set a minimum performance score for their workers, making those with low scores ineligible to participate. For the current study, only workers with at least a 95\% score or higher and who had participated in at least 100 surveys were eligible. This was done to help ensure the quality of respondents. Furthermore, we limited our potential participant pool to U.S. respondents only.

We employed screening procedures to target a specific demographic. To reduce the likelihood of dishonesty, participants were not informed that this was a screening stage nor did they know the specifics of the study at this point. Participants were asked the following questions: (1) Is English your first language? (2) Are you currently employed? (3) Have you ever been responsible for a hiring decision at work? and (4) Have you been responsible for at least one hiring decision in the last 2 years? Participants who responded "yes" to all the screening questions were redirected to the experiment survey link. Those who responded "no" to any of these questions were informed of their ineligibility.

Of the 393 respondents, 197 made it through the screening process and successfully completed the online survey. Respondents were mostly male (65\%), with an average age of 33.15 years $(S D=8.24)$. The sample was 73\% White, 6\% African-American, 8\% Asian, 10\% Hispanic, and 3\% Other. Ninety-two percent of the sample held management roles, working an average of 41.27 hours per week $(S D=$ $6.91)$. Nearly all $(98 \%)$ respondents were responsible for at least one hiring decision in the last year.

\subsection{Experimental design}

Experimental methods were employed to test the hypotheses. Participants were recruited online, directed to a Qualtrics survey page, and asked to read through a consent document outlining pertinent study information such as voluntary involvement and compensation. Our institutional review board approved all procedures. After consenting, respondents were given a scenario, which read:

"Imagine you are a hiring manager in the following scenario. An applicant named Jesse Johnson has reached the final rounds of a job interview. She[he] has the same qualifications as the other applicants, all of which are highly qualified. As a measure to differentiate the applicant pool, you decide to screen each applicant's personal Facebook page.

On the next page, you will see a screenshot of Jesse Johnson's Facebook page. Please take time to look over her[his] page, keeping in mind that Jesse Johnson does not differ from other applicants in terms of credentials or qualifications.

The image will remain on the screen for one minute, after which you will be allowed to proceed in the survey. You will be asked a series of opinion-based questions that relate to your reaction to her [his] page. Please answer these questions as honestly as possible."

Next, participants were directed to different stimulus materials, depending on condition. Qualtrics logic randomly assigned participants to one of four experimental conditions. In each condition, participants were shown a screenshot of a fake Facebook profile. An androgynous name was chosen, Jesse Johnson, and was used in all four conditions (listed in Table 1).

Table 1. Experimental conditions.

\begin{tabular}{c|cc|c|}
\multicolumn{1}{c}{} & \multicolumn{3}{c}{ Jesse Johnson's Gender } \\
\cline { 3 - 4 } $\begin{array}{c}\text { Self- } \\
\text { Pale }\end{array}$ & Masculine & Female \\
\cline { 3 - 4 } $\begin{array}{c}\text { Style } \\
\text { Stentation }\end{array}$ & Fale- & $\begin{array}{c}\text { Female- } \\
\text { Masculine } \\
\text { Masculine }\end{array}$ \\
\cline { 3 - 4 } & Feminine & $\begin{array}{c}\text { Male- } \\
\text { Feminine }\end{array}$ & $\begin{array}{c}\text { Female- } \\
\text { Feminine }\end{array}$ \\
\cline { 3 - 4 } & &
\end{tabular}

Figure 1. Example stimulus.

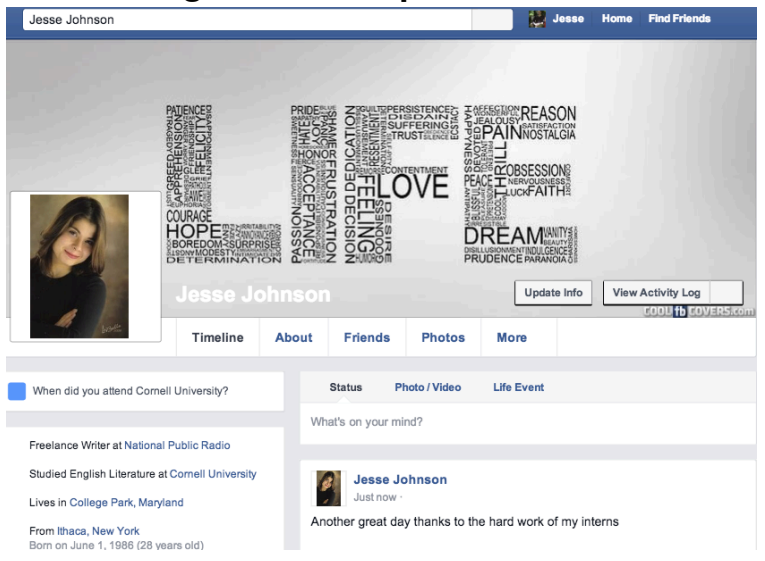

Gender was manipulated simply by using a female or male profile picture. Self-presentation style was manipulated by masculine versus feminine pictures and posts. In the feminine condition, we strived to make the posts communal and empathetic, consistent with female gender norms. For instance, a word cloud picture was used as the cover picture with 
words such as life, love, life, dream, hope, and courage. Further, the first post states, "another great day thanks to the hard work of my interns." There also is a post about graduating with: "Honors tassels ordered. So grateful for my family. I couldn't have done it without them." See Figure 1 for an example of the female, consistent stimulus.

In the masculine condition, the posts and pictures were designed to be less communal, and more selfpromotional and assertive (consistent with masculine gender norms). For example, the masculine condition included a cover picture word cloud with the words success, goal, quality, win, work, and growth. The first post states "If my interns don't get their acts together at work, I will be posting a call for new staff." The following post states "check out my latest piece on NPR DC!! Not saying I'm awesome - but I might be."

Finally, participants were asked to rate Jesse Johnson on various aspects of interpersonal attraction, hireability, and demographic information.

\subsection{Measures}

Social $(\alpha=.92)$ and task $(\alpha=.81)$ attraction were measured using the scale developed by McCroskey, McCroskey, and Richmond [27]. Sample social attraction item: "Jesse Johnson could be a friend of mine" and task attraction item: "I have confidence in Jesse Johnson's ability to get the job done". Hiring ratings were assessed using a binary "yes" or "no" variable: "Would you recommend hiring Jesse Johnson for the job to which he[she] is applying for?"

\section{Results}

We conducted a pilot study $(\mathrm{N}=254)$ to assess the stimulus materials on a 10-item measure $(\alpha=$ 0.82 ) based off previously established dimensions of masculinity and femininity [e.g., 1, 18]. Fifty percent of participants were male with the average age of $23.23(S D=4.68)$. The sample was $74 \%$ White, $7 \%$ African-American, 7\% Asian, 8\% Hispanic, and 4\% other. The majority of the sample $(86 \%)$ worked at least part time.

Table 2 summarizes the means and standard deviations of the manipulation check scores for each condition. Participants reported higher scores in the feminine conditions, which were significantly higher than scores of both masculine conditions. The manipulation of femininity and masculinity was successful, $F(3,250)=31.69, p<.01$.

Table 2. ANOVA for manip. check.

\begin{tabular}{l|ccc}
\hline \multicolumn{1}{c}{ Condition } & $n$ & Mean & Manipulation Check Score \\
\hline \multicolumn{1}{c}{ Male-Masculine } & 56 & $2.27^{\mathrm{a}}$ & 0.64 \\
Male-Feminine & 56 & $2.90^{\mathrm{b}}$ & 0.39 \\
Female-Masculine & 72 & $2.31^{\mathrm{a}}$ & 0.57 \\
Female-Feminine & 70 & $2.95^{\mathrm{b}}$ & 0.45 \\
\hline
\end{tabular}

Superscripts denote means that do not differ, $p=.05$

Table 3 reports means, standard deviations, and intercorrelations for the study variables. The control variables of gender, race, and age were not correlated with any of the study variables. As expected, social and task attraction were significantly and positively correlated $(r=0.55, p<.01)$. Providing initial support for $\mathrm{H} 3$, social attraction $(r=0.62, p<.01)$ and task attraction $(r=0.45, p<.01)$ were both related to hiring ratings.

Table 3. Descriptive statistics.

\begin{tabular}{|c|c|c|c|c|c|c|c|}
\hline Variable & $M$ & $S D$ & 1 & 2 & 3 & 4 & 5 \\
\hline 1.Gender ${ }^{\mathrm{a}}$ & - & - & - & & & & \\
\hline 2. Race $^{\text {b }}$ & - & - & 0.11 & & & & \\
\hline $\begin{array}{l}\text { 3. Age } \\
\text { 4.Social }\end{array}$ & 33.15 & 8.24 & 0.07 & $0.20^{* *}$ & - & & \\
\hline $\begin{array}{l}\text { Attraction } \\
\text { 5.Task }\end{array}$ & 3.52 & 0.88 & 0.01 & -0.05 & $\begin{array}{l}0.05 \\
-\end{array}$ & & \\
\hline $\begin{array}{l}\text { Attraction } \\
6 . \text { Hiring }\end{array}$ & 3.68 & 0.48 & & 0.07 & $\begin{array}{l}0.02 \\
-\end{array}$ & $0.55^{* *}$ & \\
\hline Ratings ${ }^{\mathrm{c}}$ & - & - & 0.00 & 0.02 & 0.11 & $0.62^{* *}$ & $0.45^{* *}$ \\
\hline
\end{tabular}

Our data is cross-sectional as it consists of multiitem measures (i.e., latent variables) collected at the same time from a single source. Thus, we tested the measurement model to ensure variance is not a product of the sampling method. Items comprising the social and task attraction were first entered into an exploratory factor analysis (EFA). KMO measure of sampling adequacy was 0.90 . Two distinct factors emerged from the Scree analysis. Furthermore, items loaded onto their respective factors, demonstrating factor loading patterns consistent with the measurement instruments. Next, we assessed the measurement model by conducting confirmatory factor analyses (CFA), comparing model fit of a single factor model (both social and task attraction loading onto one factor) and a two-factor model (social and task attraction loading on to their respective factors). Results show that the two-factor model $\left(\chi^{2}=176.92, d f=53, p<.01 ; \chi^{2} / d f=3.34\right.$; CFI 
$=.94 ;$ SRMR $=.10 ;$ RMSEA $=.10)$ displayed acceptable fit levels [28] and provided better fit than the single factor model $\left(\chi^{2}=351.54, d f=54, p<.01\right.$; $\left.\chi^{2} / d f=6.51 ; \mathrm{CFI}=.85 ; \mathrm{SRMR}=.14 \mathrm{RMSEA}=.17\right)$.

We established competing hypothesis (H1 and H2) to assess how (in)consistent self-presentation styles influence perceptions of social and task attraction. We first tested this for social attraction. One way ANOVA tests revealed significant mean differences between groups, $F(3,192)=14.73, p<$ .01. Table 4 summarizes the means and standard deviations for each condition. Post hoc analysis revealed the male-masculine condition had the lowest score of social attraction, even lower than femalemasculine. Highest ratings of social attraction were in the female-feminine condition. This did not differ significantly from the male-feminine condition but was significantly higher than both the male- and female-masculine conditions. Next, we tested task attractiveness. As shown in Table 5, one way ANOVA results demonstrated no significant mean differences between groups $[F(3,191)=1.79, n s]$. Together, these results do not support either of the competing hypotheses, but rather demonstrate a unique attraction pattern.

Table 4. ANOVA for social attraction.

\begin{tabular}{l|ccc}
\hline \multicolumn{1}{c}{ Condition } & \multicolumn{1}{c}{$\boldsymbol{N}$} & MEAN & $\boldsymbol{S D}$ \\
\hline Female-Feminine & 52 & $3.93^{\mathrm{b}}$ & 0.51 \\
Male-Feminine & 47 & $3.75^{\mathrm{b}}$ & 0.72 \\
Female-Masculine & 50 & $3.44^{\mathrm{c}}$ & 0.94 \\
Male-Masculine & 47 & $2.93^{\mathrm{a}}$ & 0.95 \\
\hline \multicolumn{2}{l}{ Superscripts denote means that do not differ, $p=.05$}
\end{tabular}

Table 5. ANOVA for task attraction.

\begin{tabular}{l|ccc}
\hline \multicolumn{1}{c}{ Condition } & $\boldsymbol{N}$ & MEAN & $\boldsymbol{S D}$ \\
\hline Female-Feminine & 51 & $3.78^{\mathrm{a}}$ & 0.45 \\
Male-Feminine & 48 & $3.71^{\mathrm{a}}$ & 0.48 \\
Female-Masculine & 50 & $3.66^{\mathrm{a}}$ & 0.44 \\
Male-Masculine & 46 & $3.57^{\mathrm{a}}$ & 0.53 \\
\hline Superscripts denote means that do not differ, $p=.05$
\end{tabular}

Hypothesis 3 stated that positive social and task attraction scores will be associated with hiring ratings and was tested using logistic regression because of the binary dependent variable (Table 6). Controlling for gender, race, and age, only social attraction impacted hiring ratings such that higher social attraction resulted in higher hiring ratings $(B=-1.78, p$ $<.01)$ whereas task attraction was only marginally related to hiring ratings $(B=-0.91, p<.10)$.
Table 6. Results for hiring ratings.

\begin{tabular}{|c|c|c|c|c|c|c|}
\hline \multirow[b]{2}{*}{ Variable } & \multicolumn{3}{|c|}{ Model 1} & \multicolumn{3}{|c|}{ Model 2} \\
\hline & $B$ & $S E$ & Wald & $B$ & $S E$ & Wald \\
\hline Gender $^{\mathrm{a}}$ & 0.01 & 0.35 & 0.00 & 0.30 & 0.47 & $\overline{0.40}$ \\
\hline Race $^{\mathrm{b}}$ & -0.01 & 0.39 & 0.00 & -0.28 & 0.53 & 0.29 \\
\hline Age & 0.03 & 0.02 & 2.59 & 0.03 & 0.03 & 1.02 \\
\hline Social & & & & -1.78 & 0.31 & $33.18^{* *}$ \\
\hline Attraction & & & & & & \\
\hline $\begin{array}{l}\text { Task } \\
\text { Attraction }\end{array}$ & & & & -0.91 & 0.49 & $3.36^{\mathrm{t}}$ \\
\hline Constant & -2.17 & 0.73 & $8.94^{* *}$ & 6.98 & 1.95 & $12.88^{* *}$ \\
\hline
\end{tabular}

\section{Discussion}

Given that SNS-mediated personas tend to portray more accurate self-presentations of oneself, our work set out to evaluate whether hiring managers view violations of gender norms on job applicant SNS profiles to be indicative of authenticity, resulting in higher attraction to the applicant. Interestingly, our results demonstrated attraction patterns that do not support this or traditional backlash patterns experienced in offline settings. Rather, it appears that feminine-style communication, regardless of gender are seen as more attractive, whereas masculine tactics are seen as less attractive. The lowest ratings of attraction occur for the gender consistent category of masculine-male. These ratings were even lower than masculine-female, which is counter to the expectancy violation theory. This theory would predict that masculine female would receive the strongest backlash and negative reactions. On the other hand the finding that feminine-male category to be rated as equally attractive as the feminine-female conforms to expectancy violation theory, in that this is a positive violation, which engenders positive reactions.

It seems that rather than valuing consistency with gender norms, more communal, empathetic behaviors were seen as attractive and thus increasingly desirable. This is interesting because in general the selection literature has found strong results for competence as being valuable in the hiring process. It may be that because Facebook presents viewers with a realistic preview of the person, managers are not looking there for information about task competence, but are rather making inferences about the candidates' personality and communal, cooperative individuals are seen as more desirable to work with. Indeed, cooperation has been linked to more positive evaluations [6].

Interestingly, the findings in this study deviate from research that suggests the use of self-promotion 
(i.e., masculine self-presentation style) results in higher levels of competence ratings [e.g., 21, 45]. There seems to be a negative impact of this tactic (negative social attraction scores) with little positive effect, as demonstrated by the null findings for task attractiveness. It appears that, if a user self-promotes on Facebook, they will be viewed as less likeable and at the same time not be seen as any more competent.

There are two explanations for the null task attraction results. First comes from the fact that SNS is mainly textual communication, void of "nonverbal cues to embellish meaning" [40, p. 100], which often results in the communication coming across as more rude or offensive online versus offline [46]. Second, Facebook may prime individuals to look at social competence rather than task competence because Facebook has emerged a tool primarily for relationship (friendship and romantic) seeking and maintenance. It is possible that other SNS like LinkedIn, because it is more professionally oriented, may have a greater impact on task attraction.

\subsection{Implications, strengths, and limitations}

For job seekers, understanding how their personal Facebook pages influence employer decisions is an invaluable asset. The results from this study suggest that masculine-style communication through Facebook may appear harsh to hiring managers. Thus, job seekers should deploy more feminine communications on their Facebook pages and stay away from utilizing more masculine behaviors.

In the case of the hiring manager, it is of utmost importance that there is a certain familiarity with the various biases that exist in a hiring scenario. Results suggest that hiring managers are more sensitive to masculine-type communications. Though there are no gender differences, reducing the concern for illegal discrimination based on sex, employers may overlook potentially qualified candidates based on selfpresentation style alone. Hiring managers need to understand that communications on SNS appear harsher or ruder than FTF settings, and should adjust their assessments accordingly.

Our findings should be viewed in light of the strengths and limitations. First, our data is crosssectional. However, it was experimental in design, which is necessary for exploratory studies. Second, we did not use a traditional organizational sample.

Although the results of this study are not industry specific, the present sample helps improve the generalizability of our findings, which is appropriate for the exploratory nature of this study. Instead, we recruited managers to participate in our study using MTurk. Though significant care was taken to ensure data integrity (screening methods), and participants were paid for partial completes to disincentivise deceptive participant behavior, it is possible that some participants falsified the screener questions, introducing unexpected error and variation into the results. MTurk workers have been found to be reliable and mimic other social scientific samples, but as is always the case with data collection, the potential for error exists.

These limitations lead us to our first area for future research, which should investigate SNS normative pressures using different designs and sampling methods. Moreover, future research should consider multiple SNS, such as LinkedIn, or emerging platforms like Snapchat to more fully understand how gender norms function on different SNS that have originated from different purposes. Additionally, it would be fruitful to examine the actual selection processes at an organization to further validate these findings using actual hiring managers and job applicants.

Additionally, gender is only one application of a broader concept of normative adherence on SNS versus offline contexts. Taking the position that SNS is a less constrained context than offline environments allows us to extrapolate our findings to other socially prescribed norms such as race and age. Future research should explore such factors.

If replicated, it will be interesting to see if these lowered normative pressures will translate into FTF contexts as well. Do SNS have the ability to change social normative pressures? Kim and Yun [20] found in a Korean sample that there were less normative pressures on SNS and that "fosters the reframing of relational issues offline" (p. 298).

Lastly, the authors would like to note that the practice of leveraging information about applicants gleaned from social media during selection processes has ethical (and legal) considerations. The current research is designed to explore the consequences of such scenarios and is not intended to condone such behavior. This research is offered in the hope of stimulating more frequent conversations about these practices.

\section{Conclusion}

In conclusion, our study provides an initial, exploratory glimpse into the impact of inconsistent 
gender norm communication on SNS on attraction and hiring decisions. Counter to prior research in synchronous selection processes (e.g., interviews), we found that positive assessments on Facebook occurred with more feminine communication styles, regardless of gender. Masculine communication styles were seen as less attractive and hirable.

\section{References}

[1] A. B. Heilbrun, "Measurement of masculine and feminine sex role identities as independent dimensions," Journal of consulting and clinical psychology, 44(2), 1976, p. 183.

[2] A. Eagly, "Sex differences in social behavior: A socialrole interpretation Erlbaum," Hillsdale, New Jersey, 1987.

[3] A. Keenan, "Some relationships between interviewers' personal feelings about candidates and their general evaluation of them," Journal of Occupational Psychology, 50(4), 1977, pp. 275-283.

[4] B. F. Meeker and P. A. Weitzel-O'Neill, "Sex roles and interpersonal behavior in task-oriented groups," In J. Berger \& M. Zelditch (Eds.), Status, rewards, and influence, Washington, DC, 1985, pp. 379-405.

[5] B. Latané, "The psychology of social impact," American psychologist, 36(4), 1981, p. 343.

[6] C. A. Cottrell, S. L. Neuberg, and N. P. Li, "What do people desire in others? A sociofunctional perspective on the importance of different valued characteristics," Journal of personality and social psychology, 92(2), 2007, p. 208.

[7] C. Gallois, V. J. Callan, and J. A. M. PALMER, "The Influence of Applicant Communication Style and Interviewer Characteristics on Hiring Decisions 1," Journal of Applied Social Psychology, 22(13), 1992, pp. 10411060 .

[8] C. T. Kulik and M. Olekalns, "Negotiating the gender divide lessons from the negotiation and organizational behavior literatures," Journal of Management, 38(4), 2012, pp. 1387-1415.

[9] C. Orpen, "Attitude similarity, attraction, and decisionmaking in the employment interview," The Journal of psychology, 117(1), 1984, pp. 111-120.

[10] E. H. Buttner and M. McEnally, "The interactive effect of influence tactic, applicant gender, and type of job on hiring recommendations," Sex Roles, 34(7-8), 1996, pp. 581-591.

[11] Goffman, E, The presentation of self in everyday life. Doubleday and Co, New York, 1978.

[12] J. A. Bargh, K. Y. McKenna, and G. M. Fitzsimons, "Can you see the real me? Activation and expression of the "true self" on the Internet," Journal of social issues, 58(1), 2002, pp. 33-48.
[13] J. A. Hilty and P. J. Carnevale, "Black-hat/white-hat strategy in bilateral negotiation," Organizational Behavior and Human Decision Processes, 55, 1993, pp. 444-469.

[14] J. H. Fleming, J. M. Darley, J. L. Hilton, and B. A. Kojetin, "Multiple audience problem: a strategic communication perspective on social perception," Journal of personality and social psychology, 58(4), 1990, p. 593.

[15] J. K. Burgoon and L. Dillman, "Gender, immediacy, and nonverbal communication," Gender, power, and communication in human relationships, 1995, pp. 63-81.

[16] J. M. Madera, "Using social networking websites as a selection tool: The role of selection process fairness and job pursuit intentions," International Journal of Hospitality Management, 31(4), 2012, pp. 1276-1282.

[17] J. Rui and M. A. Stefanone, "Strategic selfpresentation online: A cross-cultural study," Computers in Human Behavior, 29(1), 2013, pp. 110-118.

[18] J. T. Spence, R. Helmreich, and J. Stapp, "Ratings of self and peers on sex role attributes and their relation to self-esteem and conceptions of masculinity and femininity," Journal of personality and social psychology, 32(1), 1975, p. 29.

[19] J. Vitak, "The impact of context collapse and privacy on social network site disclosures," Journal of Broadcasting \& Electronic Media, 56(4), 2012, pp. 451-470.

[20] K. H. Kim and H. Yun, "Cying for me, Cying for us: Relational dialectics in a Korean social network site," Journal of Computer Mediated Communication, 13(1), 2007, pp. 298-318.

[21] L. A. Rudman, "Self-promotion as a risk factor for women: the costs and benefits of counterstereotypical impression management," Journal of personality and social psychology, 74(3), 1998, p. 629.

[22] L. A. Rudman and K. Fairchild, "Reactions to counterstereotypic behavior: the role of backlash in cultural stereotype maintenance," Journal of personality and social psychology, vol. 87, p. 157, 2004.

[23] L. A. Rudman and P. Glick, "Feminized management and backlash toward agentic women: the hidden costs to women of a kinder, gentler image of middle managers," Journal of personality and social psychology, 77(5), 1999, p. 1004.

[24] L. A. S. Shapiro and G. Margolin, "Growing up wired: Social networking sites and adolescent psychosocial development," Clinical child and family psychology review, 17(1), 2014, pp. 1-18.

[25] L. L. Carli, "Gender, language, and influence," Journal of Personality and Social Psychology, 59(5), 1990, p. 941.

[26] L. L. Carli, "Gender and social influence," Journal of Social Issues, 57(4), 2001, pp. 725-741.

[27] L. L. McCroskey, J. C. McCroskey, and V. P. Richmond, "Analysis and improvement of the measurement of interpersonal attraction and homophily," Communication Quarterly, 54(1), 2006, pp. 1-31. 
[28] L. t. Hu and P. M. Bentler, "Cutoff criteria for fit indexes in covariance structure analysis: Conventional criteria versus new alternatives," Structural equation modeling: a multidisciplinary journal, 6(1), 1999, pp. 1-55.

[29] M. A. Stefanone and D. Lackaff, "Reality television as a model for online behavior: Blogging, photo, and video sharing," Journal of Computer Mediated Communication, 14, 2009, pp. 964-987.

[30] M. Buhrmester, T. Kwang, and S. D. Gosling, "Amazon's Mechanical Turk a new source of inexpensive, yet high-quality, data?" Perspectives on psychological science, 6(1), 2011, pp. 3-5.

[31] M. C. Bolino and W. H. Turnley, "More than one way to make an impression: Exploring profiles of impression management," Journal of Management, 29(2), 2003, pp. 141-160.

[32] M. D. Back, J. M. Stopfer, S. Vazire, S. Gaddis, S. C. Schmukle, B. Egloff, et al., "Facebook profiles reflect actual personality, not self-idealization," Psychological science, 34, 2010, pp.110-118.

[33] M. Deutsch and H. B. Gerard, "A study of normative and informational social influences upon individual judgment," The journal of abnormal and social psychology, 51(3), 1955, p. 629.

[34] M. E. Heilman and A. S. Wallen, "Wimpy and undeserving of respect: Penalties for men's genderinconsistent success," Journal of Experimental Social Psychology, 46, 2010, pp. 664-667,.

[35] M. E. Lockheed and K. P. Hall, "Conceptualizing sex as a status characteristic: Applications to leadership training strategies," Journal of Social Issues, 32(3), 1976, pp. 111-124.

[36] M. R. Barrick, B. W. Swider, and G. L. Stewart, "Initial evaluations in the interview: relationships with subsequent interviewer evaluations and employment offers," Journal of Applied Psychology, 95(6), 2010, pp.1163.

[37] M. R. Leary, Self-presentation: Impression management and interpersonal behavior: Brown \& Benchmark Publishers, 1995.

[38] N. H. Anderson, "Likableness ratings of 555 personality-trait words," Journal of personality and social psychology, 9(3), 1968, p. 272.

[39] N. Haferkamp, S. C. Eimler, A.-M. Papadakis, and J. V. Kruck, "Men are from Mars, women are from Venus? Examining gender differences in self-presentation on social networking sites," Cyberpsychology, Behavior, and Social Networking, 15(2), 2012, pp. 91-98.

[40] P. Bordia, "Face-to-face versus computer-mediated communication: A synthesis of the experimental literature," Journal of Business Communication, 34(1), 1997, pp. 99118.

[41] P. L. Roth, P. Bobko, C. H. Van Iddekinge, and J. B. Thatcher, "Social media in employee-selection-related decisions a research agenda for uncharted territory," Journal of Management, 2013, p. 0149206313503018.

[42] R. B. Cialdini and N. J. Goldstein, "The science and practice of persuasion," Cornell Hospitality Quarterly, 43(2), 2002, p. 40.

[43] R. E. Guadagno and R. B. Cialdini, "Gender differences in impression management in organizations: A qualitative review," Sex Roles, 56(7-8), 2007, pp. 483-494.

[44] R. Slovensky and W. H. Ross, "Should human resource managers use social media to screen job applicants? " Managerial and legal issues in the USA, info, 14(1), 2012, pp. 55-69.

[45] S. J. Wayne and R. C. Liden, "Effects of impression management on performance ratings: A longitudinal study," Academy of Management journal, 38(1), 1995, pp. 232-260.

[46] S. Kiesler, J. Siegel, and T. W. McGuire, "Social psychological aspects of computer-mediated communication," American psychologist, 39(10), 1984, p. 1123 .

[47] S. T. Fiske, A. J. Cuddy, P. Glick, and J. Xu, "A model of (often mixed) stereotype content: competence and warmth respectively follow from perceived status and competition," Journal of personality and social psychology, 82(6), 2002, p. 878.

[48] S. Tifferet and I. Vilnai-Yavetz, "Gender differences in Facebook self-presentation: An international randomized study," Computers in Human Behavior, 35, 2014, pp. 388399.

[49] Swan, W. B., "Self-Verification Theory," in Handbook of Theories of Social Psychology, 2, Los Angeles, CA, UA: Sage Publications, 2011, pp. 23-42.

[50] S. Zhao, S. Grasmuck, and J. Martin, "Identity construction on Facebook: Digital empowerment in anchored relationships," Computers in human behavior, 24(5), 2008, pp. 1816-1836.

[51] T. Eckes, "Paternalistic and envious gender stereotypes: Testing predictions from the stereotype content model," Sex Roles, 47(3-4), 2002, pp. 99-114.

[52] U. Oberst, V. Renau, A. Chamarro, and X. Carbonell, "Gender stereotypes in Facebook profiles: Are women more female online?", Computers in Human Behavior, 60, 2016, pp. 559-564.

[53] Walster, E., \& Berscheid, E., Foundations of Interpersonal Attraction., Reading, MA, 1969.

[54] Walster, E., Walster, G. W., \& Berscheid, E., Equity theory: Theory and research., Allyn and Bacon, Inc, Boston, 1978.

[55] Zz.Zz., Global Social Network Users World Wide, 2016. Statistics.com, 2016. 